\title{
El uso del juego \\ y la metodología \\ cooperativa en la \\ Educación Superior: \\ una alternativa para la \\ enseñanza creativa
}

The use of the game and the cooperative Methodology in Highet Educatio: an alternative for creative teaching

\section{ELENA CARRIÓN CANDEL}

elena.carrion@unir.net·ecarrion@ucjc.edu

Universidad Internacional de La Rioja Universidad Camilo José Cela 
$\Rightarrow$ Recibido 21/11/2018

$\checkmark$ Aceptado 10/01/2019

\section{Resumen}

El auge de las TIC y las nuevas estrategias de enseñanza en el Espacio Europeo de Educación Superior (EEES), demandan un cambio estructural en la manera de concebir el proceso de enseñanza-aprendizaje en la Educación Superior. Por ello, se debe propiciar la formación del alumnado universitario -futuros docentes de Educación Primaria -como expertos en la utilización de las herramientas tecnológicas. En este contexto, planteamos una propuesta de innovación educativa, que se une al aprendizaje basado en los juegos (AbJ) y la metodología cooperativa y comunicativa, con la finalidad de educar en los conocimientos, competencias y destrezas marcadas en el currículo de educación musical. Tiene como objetivo mejorar la praxis docente permitiendo un aprendizaje más motivador y significativo al alumnado para mejorar su proceso didáctico a través del desarrollo de la competencia digital y la gamificación. Los resultados de nuestra investigación confirman la eficacia de la metodología cooperativa y lúdica, que se presenta como una alternativa de gran potencial formativo para el alumnado. 


\section{Abstract}

The rise of ICT and new teaching strategies in the European Higher Education Area (EHEA) demand a structural change in the way of conceiving the teaching-learning process in higher education. For this reason, it is necessary to encourage the formation of the university students-future teachers of primary education-as experts in the use of technological tools. In this context, we propose a proposal for educational innovation, which unites the learning based on the Games (AbJ) and the cooperative and communicative methodology, with the purpose of educating in the knowledge, competencies and skills marked in the curriculum of musical education.. It aims to improve the teaching praxis allowing a more motivating and meaningful learning to the students to improve their didactic process through the development of the digital competition and the gamification. The results of our research show the effectiveness of the cooperative and recreational methodology, which is presented as an alternative.

\section{Keywords}

Music education - Cooperative learning · Active methodologies . Celebriti $\cdot$ Kahoot $\cdot$ Higher education

\section{Introducción}

El mundo de la educación en sus diferentes niveles educativos se abre a nuevos planteamientos y paradigmas, las formas de enseñar y aprender se han modificado sustancialmente. Así, las nuevas tecnologías y más concretamente las TIC aplicadas a la educación, han ido adquiriendo un papel significativo en las aulas y en las presentes técnicas de enseñanza-aprendizaje para actualizar y dinamizar los procesos didácticos. Es una realidad que vivimos en la sociedad de la información donde no solo el ámbito educativo, sino todas las áreas de la vida de los sujetos están marcadas por el uso y el consumo de la tecnología. Tal es así que aparece el concepto de "brecha tecnológica" (Cabero, 2014) para referirse a la situación de desventaja que se crea entre aquellos que tienen acceso y saben utilizar las TIC frente a los que no. Los planes de formación, por tanto, ni pueden ni deben estar ajenos a esta situación, promoviendo no solo los recursos y asignaturas, sino procedimientos y metodologías basadas en el uso de las TIC con las que adquirir las competencias tecnológicas para vivir en la sociedad de la información y el conocimiento. 
Con respecto a la formación del docente universitario en el uso de las TIC se ha de plantear de manera que le ofrezca respuestas a situaciones de aula, que le permita realizar una reflexión sobre su potencialidad, que admita participar en el proceso de elaboración de la herramienta, interactuar con ella, realizar evaluaciones de los conocimientos de los alumnos, motivar al alumnado, realizar innovaciones de la propia herramienta, adaptaciones de la misma a diferentes contextos, etc., algunas de las dimensiones que debe tener la formación del profesorado para la capacitación TIC son la :instrumental, curricular, estética, pragmática, psicológica, productora-diseñadora, organizativa, seleccionadora-evaluadora, crítica, actitudinal e investigadora.

Asimismo, a la hora de la formación del profesorado en el uso y manejo de las TIC, debemos analizar y estudiar el conocimiento que debe tener el docente para una correcta utilización de la tecnología en el aula, por un lado, para mejorar la práctica docente en el desarrollo de su asignatura $y$, por otra parte, para el desarrollo de la competencia digital de los alumnos. En este sentido, son muchos los autores que siguen estos planteamientos y consideran las TIC y especialmente la ga- mificación, herramientas didácticas novedosas, que han supuesto en la educación una nueva forma de enseñar, aprender y participar, especialmente en el contexto de la Universidad, para lograr un proceso de enseñanza-aprendizaje más eficaz que conecta la teoría en el aula con la realidad del entorno cotidiano del alumnado (Roca, 2004; Romero, 2004; Paspartegiou; 2009;Guri- Rosenblit, 2010; Kaap, 2012; Cabero, 2014; Prado, 2014; Su y Cheng, 2015; Rangel, 2015; Riemer y Schrader, 2015; Largo y Molina, 2016;Contreras, 2016; Espeso, 2017; Sánchez, Álvarez, Dávila y Mellado, 2017; Cordero, 2018). Concretamente, Paspastergiou (2009) muestra un estudio donde se utilizó el juego para aprender conceptos teóricos de memoria, demostrándose que los alumnos que utilizaron el juego aprendieron más y estaban más motivados, en comparación con los alumnos que usaban un enfoque de enseñanza sin juegos.

En este marco conceptual, proponemos un planteamiento de innovación y enseñanza activa sustentado en una estrategia educativa que excluye el aprendizaje meramente memorístico de los contenidos de los programas educativos y los exámenes como forma principal de evaluación, priorizando el aprendiza- 
je cooperativo -basado en grupos heterogéneos de alumnos que trabajan de manera sistematizada para resolver las tareas académicas y desarrollar su propio aprendizaje-, y la metodología de la gamificación -consistente en la integración de dinámicas propias de juegos en contextos no lúdicos- , al final la gamificación lo que busca es crear ese contexto favorable y adictivo que producen los juegos para que el alumnado aprenda de una manera mucho más activa, creativa, y sea capaz de sintetizar mejor su aprendizaje. Para lograrlo hacemos uso de ambas metodologías -la cooperativa y la gamificación-, cuya función sea la de contribuir a un aprendizaje mucho más eficiente, consolidado y activo, para la formación de capacidades comunicativas, así como la adquisición de habilidades sociales en los estudiantes al interactuar, compartir, relacionarse y ampliar el conocimiento. Igualmente, con nuestro proyecto pretendemos aportar nuevas formas de enseñar y aprender, para modificar ciertas prácticas "tradicionales" desarrolladas en el contexto educativo, propiciando el interés y motivación del alumnado por la asignatura.

\section{Descripción general de la propuesta didáctica}

El presente trabajo se basa en una propuesta innovadora que emplea la gamificación y las nuevas tecnologías para llevar a cabo el proceso de enseñanza-aprendizaje en el Grado de Primaria, concretamente en la Mención en Música.

La propuesta que implementamos pretende la aplicación de nuevas estrategias y metodologías para mejorar la praxis docente y permitir un aprendizaje más motivador y significativo por parte del alumnado. Facilita la creación de nuevos entornos de formación en el alumnado, propicios para la reflexión, el análisis y el aprendizaje por descubrimiento y significativo. Para su consecución hemos elaborado recursos digitales musicales-Cerebriti y Kahoot-, como estrategias didácticas para enseñar contenidos musicales, aportando un contexto más variado e interactivo que fomente el ambiente colaborativo y comunicativo entre profesorado y alumnado, con el objeto de que el alumnado alcance una autonomía de aprendizaje y trabaje la competencia comunicativa mediante la cooperación entre iguales. Todo ello se consigue mediante las herramientas tecnológicas elaboradas, que 
permiten actualizar y dinamizar los procesos didácticos de una forma más atractiva contribuyendo a mejorar la práctica en el aula, ya que posibilitan un aprendizaje más motivador y significativo que con metodologías tradicionales, ajustándose a las necesidades y ritmos de aprendizaje de los estudiantes.

Los objetivos que nos proponemos obtener con esta propuesta esgrimiendo la música como punto de partida en la formación educativa de nuestros alumnos, serían los siguientes:

- Utilizar herramientas tecnológicas sobre música para mejorar e innovar en el proceso de enseñanza-aprendizaje, para aprender a aprender y saber hacer.

- Realizar actividades de gamificación en el aula, como medio de adquisición y desarrollo de conocimientos, competencias y habilidades para el aprendizaje de la música de forma motivadora, activa y significativa.

- Desarrollar el análisis y juicio crítico, así como el interés y motivación por la asignatura de música.

- Aprender de forma activa, colaborativa y desarrollar habilidades de comunicación.
A continuación, se aborda el desarrollo de la propuesta didáctica, para posteriormente, exponer la metodología, sus resultados y conclusiones.

Las técnicas de gamificación elaboradas -Cerebriti y Kahoot-, basadas en la ludificación, explotan todos los recursos posibles, combinan tecnologías de la información y comunicación (TIC) y juegos educativos para hacer más interesante y atractivo el proceso de enseñanza-aprendizaje a los alumnos.

1) La aplicación CEREBRITI EDU es una herramienta idónea para implementar la gamificación como metodología en un aula, al fusionar el aprendizaje colaborativo con dinámicas de juego en la clase. Esta plataforma educativa contiene elementos de calificación, medidores de evolución académica, autocorrección de ejercicios, generador de informes automatizados, etc. Además, se considera una buena herramienta para repasar un tema, aunque también puede servir para introducirlo, revisar los conocimientos que los alumnos todavía no han adquirido, etc. Los alumnos fijan mejor 
sus conocimientos mientras se divierten compartiéndolos con sus compañeros. Este recurso basado en la gamificación o ludificación, mejora los procesos de aprendizaje, la motivación, el desarrollo de la inteligencia emocional y la adquisición de habilidades de cooperación entre otras.

Planteamos distintos juegos de Cerebriti de varias modalidades: de imágenes, de tipo test, de ordenar... para facilitar el aprendizaje de los distintos contenidos musicales planteados en clase. En definitiva, todo un proceso que les ayudará a entender mejor los contenidos y que les convertirá en protagonistas de su propio aprendizaje.

* Clasificación de los instrumentos musicales (I)

En este juego de gamificación el alumno debe relacionar cada imagen con su clasificación instrumental correspondiente. "Arrastra con el ratón cada palabra con su imagen correspondiente. Si has acertado, desaparecerán las dos".

La URL del juego de Cerebriti es la siguiente: https://www.cerebriti.com/juegos-de-musica/clasificacion-de-los-instrumentos-musicales--i-

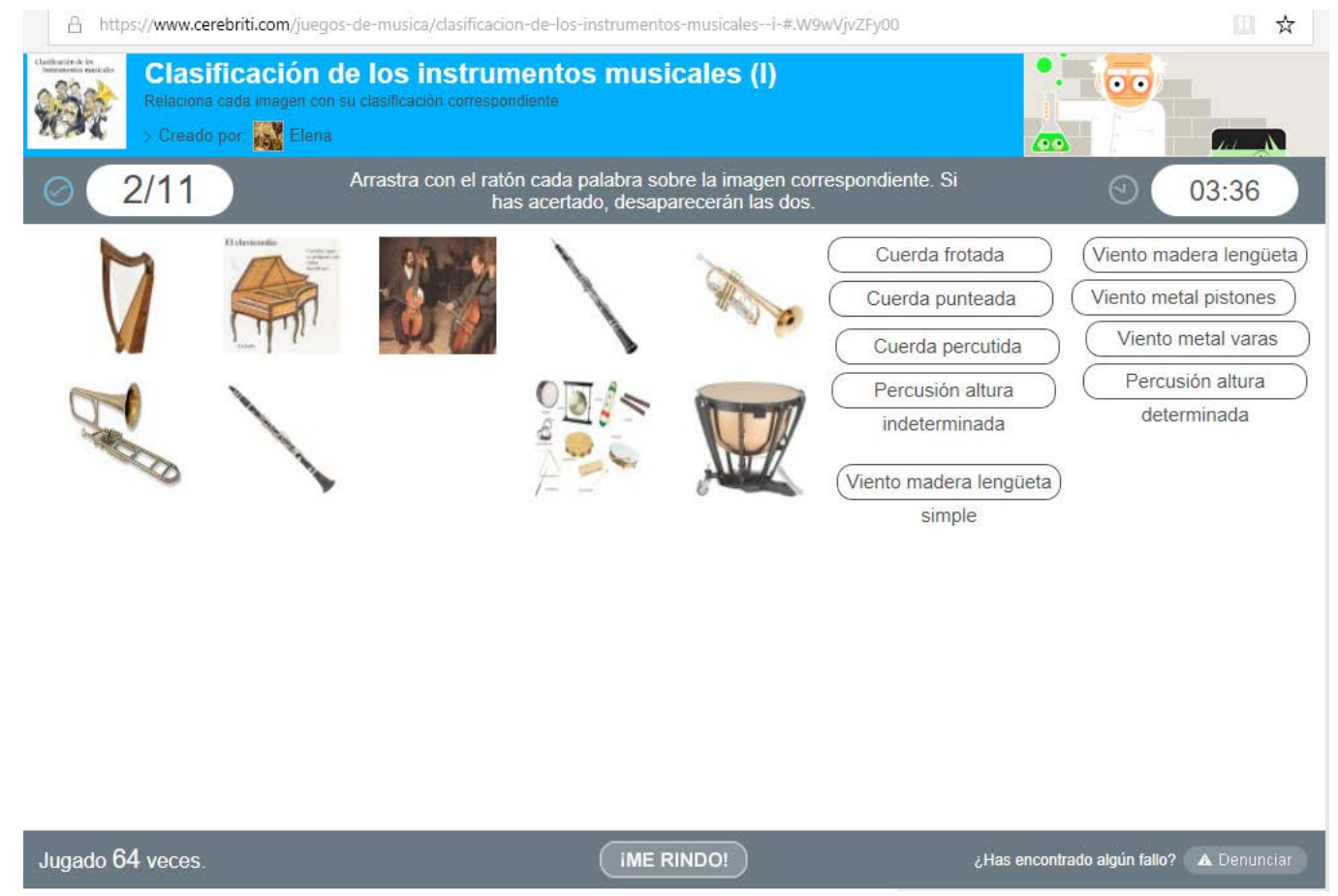

Imagen 1. Cerebriti: Clasificación de los instrumentos musicales (I). 
- Clasificación de los instrumentos musicales (II)

En este juego de gamificación el alumno debe relacionar cada imagen con su clasificación instrumental correspondiente. "Arrastra con el ratón cada palabra con su imagen correspondiente. Si has acertado, desaparecerán las dos".

La URL del juego de Cerebriti es la siguiente: https://www.cerebriti.com/ juegos-de-musica/clasificacion-de-los-intrumentos-musicales--ii-/\#.WsOLKpe-n4Y

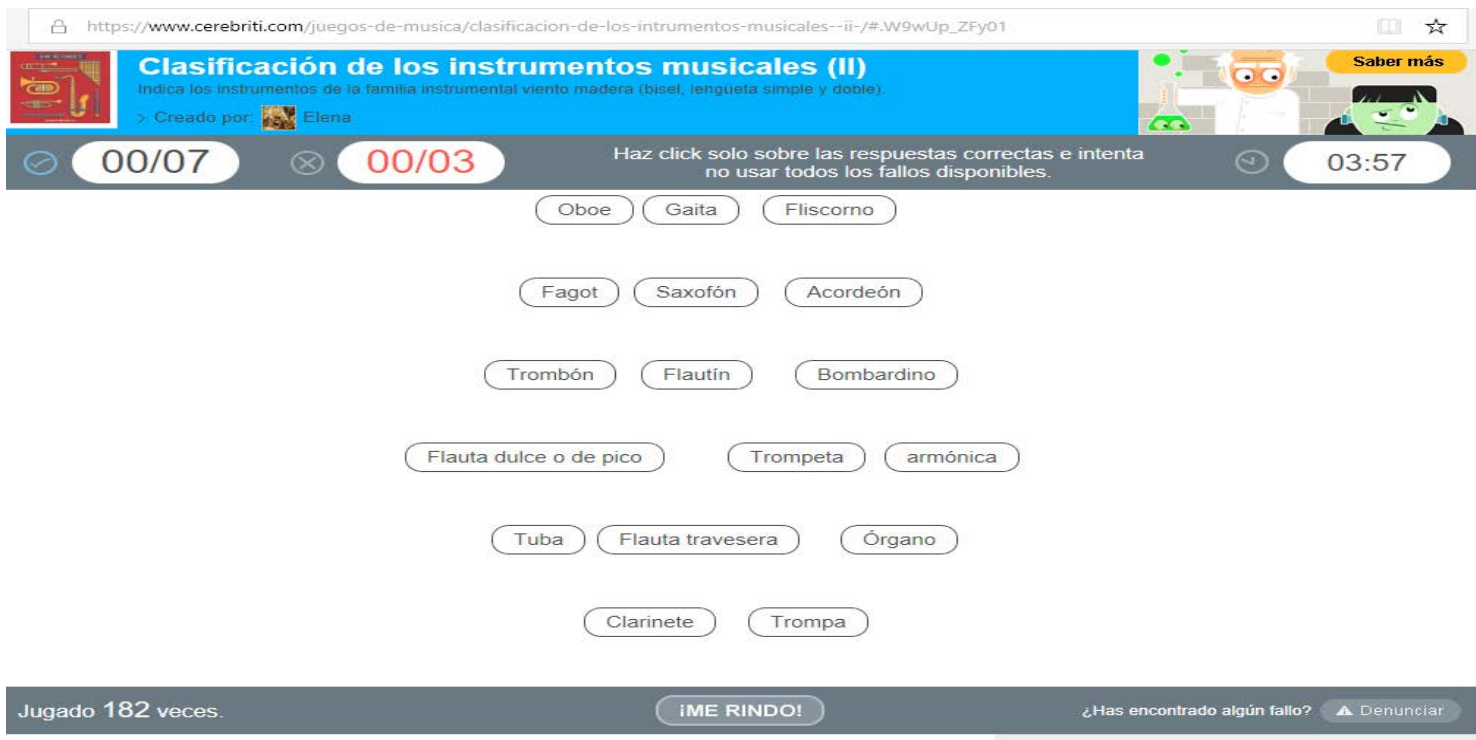

Imagen 2. Cerebriti: Clasificación de los instrumentos musicales (II).

La URL del juego de Cerebriti es la siguiente: https://www.cerebriti.com/juegos-de-musica/pasapalabras-musical 


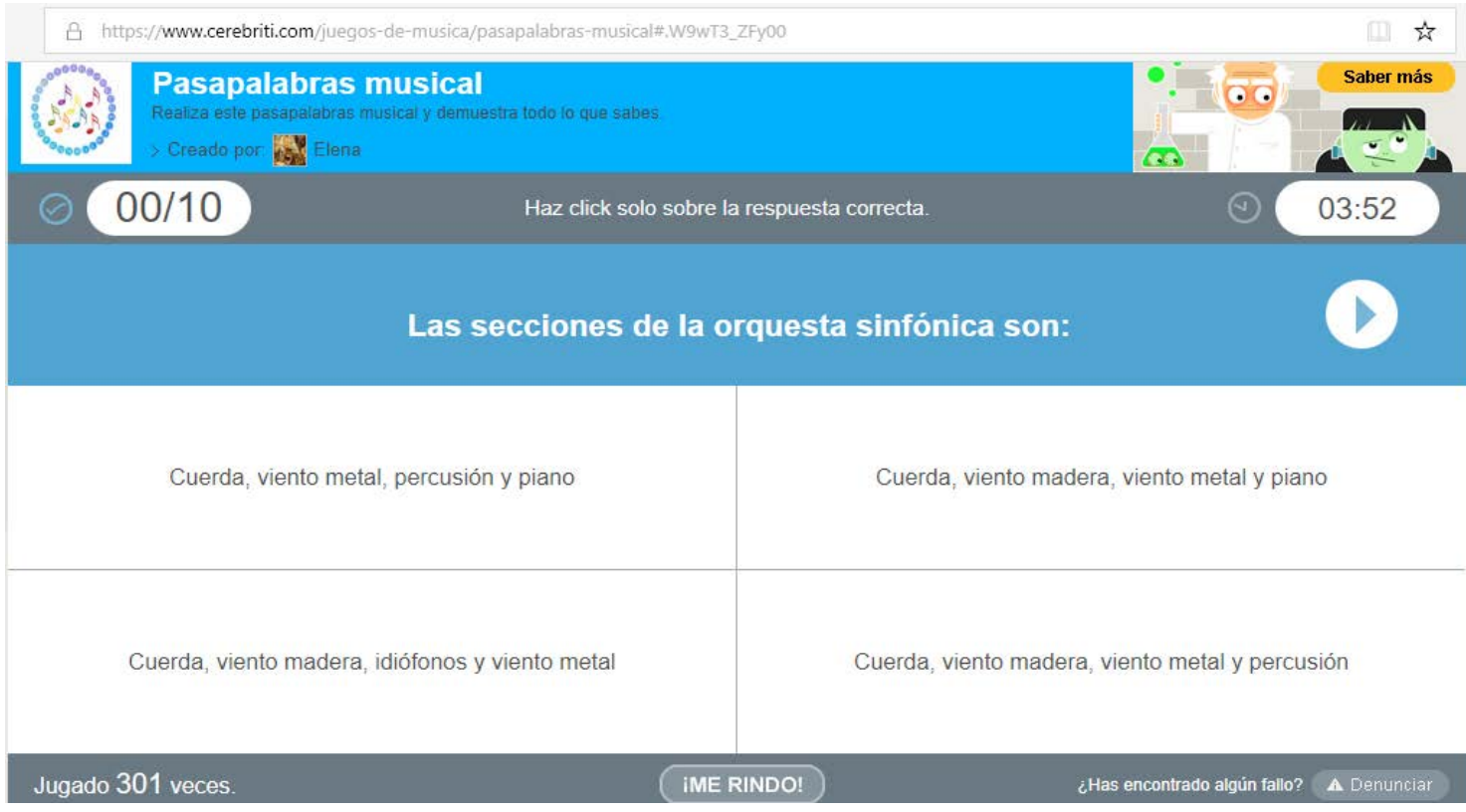

Imagen 3. Pasapalabras musical

* Cerebriti: la música en el Clasicismo y el Romanticismo.

En este juego de gamificación el alumno debe elegir la respuesta correcta y practicar con este pasapalabras musical. "Haz click sobre la respuesta correcta”.

La URL del juego de Cerebriti es la siguiente: https://www.cerebriti.com/juegos-de-musica/la-musica-en-el-clasicismo-y-romanticismo\#.WsOKq5e-n4Y
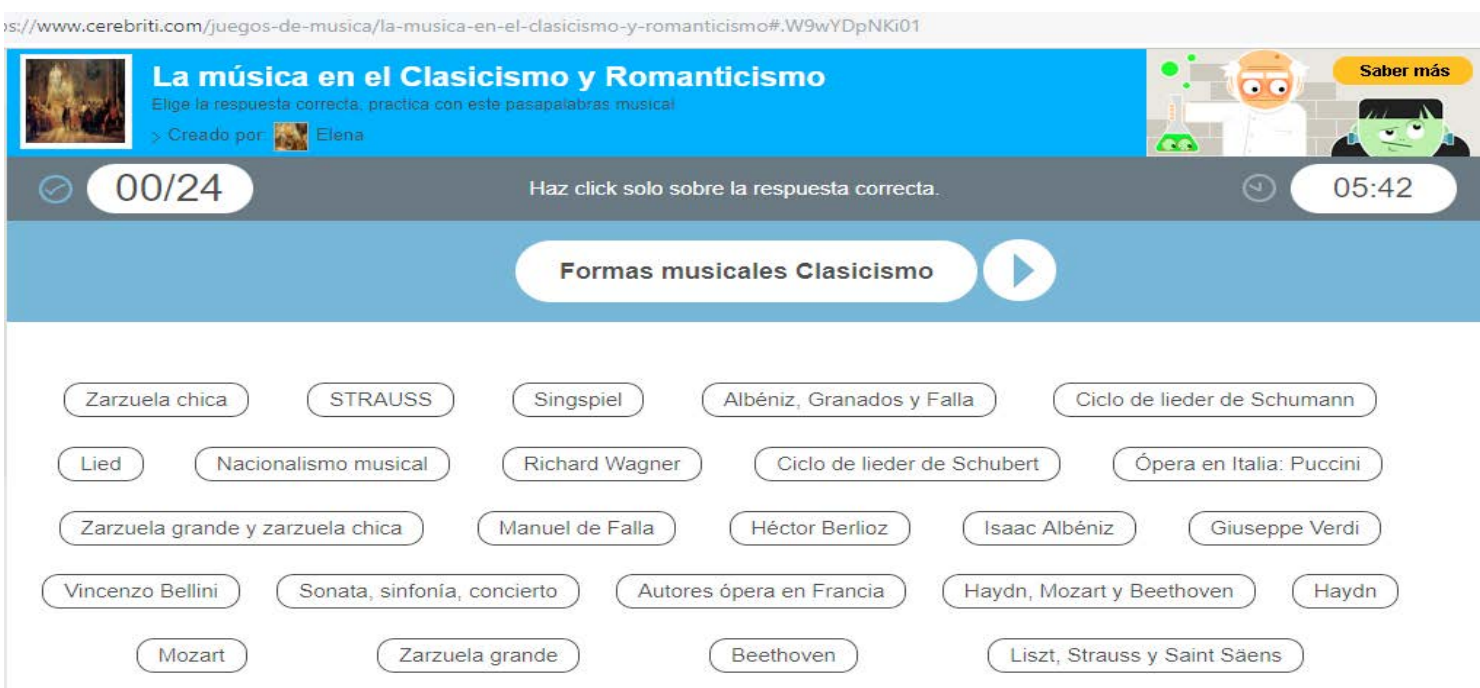

Imagen 4. Cerebriti: la música en el Clasicismo y el Romanticismo 


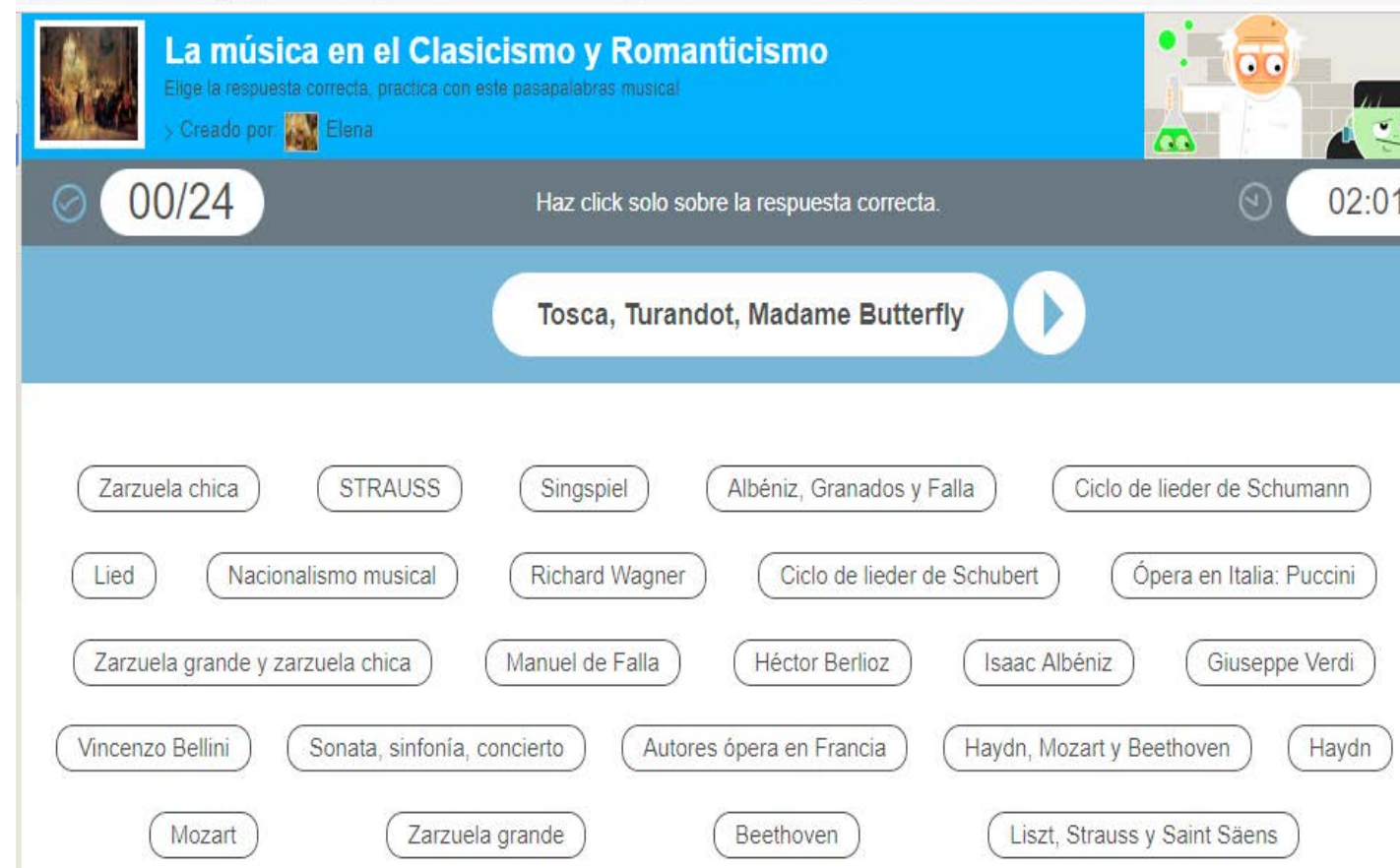

Imagen 5. Cerebriti: la música en el Clasicismo y el Romanticismo.

2) KAHOOT, es una herramienta muy útil para la creación de cuestionarios de evaluación. En nuestro caso permite aprender y repasar conceptos contenidos musicales de forma divertida y entretenida, simulando un concurso. Este Kahoot contiene preguntas tipo test, para reconocer imágenes y videos para la discusión y el debate. La idea es aprender jugando, es decir, este servicio Web de educación social y gamificada, se comporta como un juego recompensando a quienes progresan en las respuestas con una mayor puntuación que les situará en lo más alto del ranking. Por tanto, los alumnos crean su avatar y contestan a una serie de preguntas por medio de su dispositivo móvil, finalmente gana quien consigue más puntuación. La URL del juego del Kahoot es la siguiente: https://play.kahoot.it/\#/k/416f027d-995c-4f74-9608-daf613b317e6 


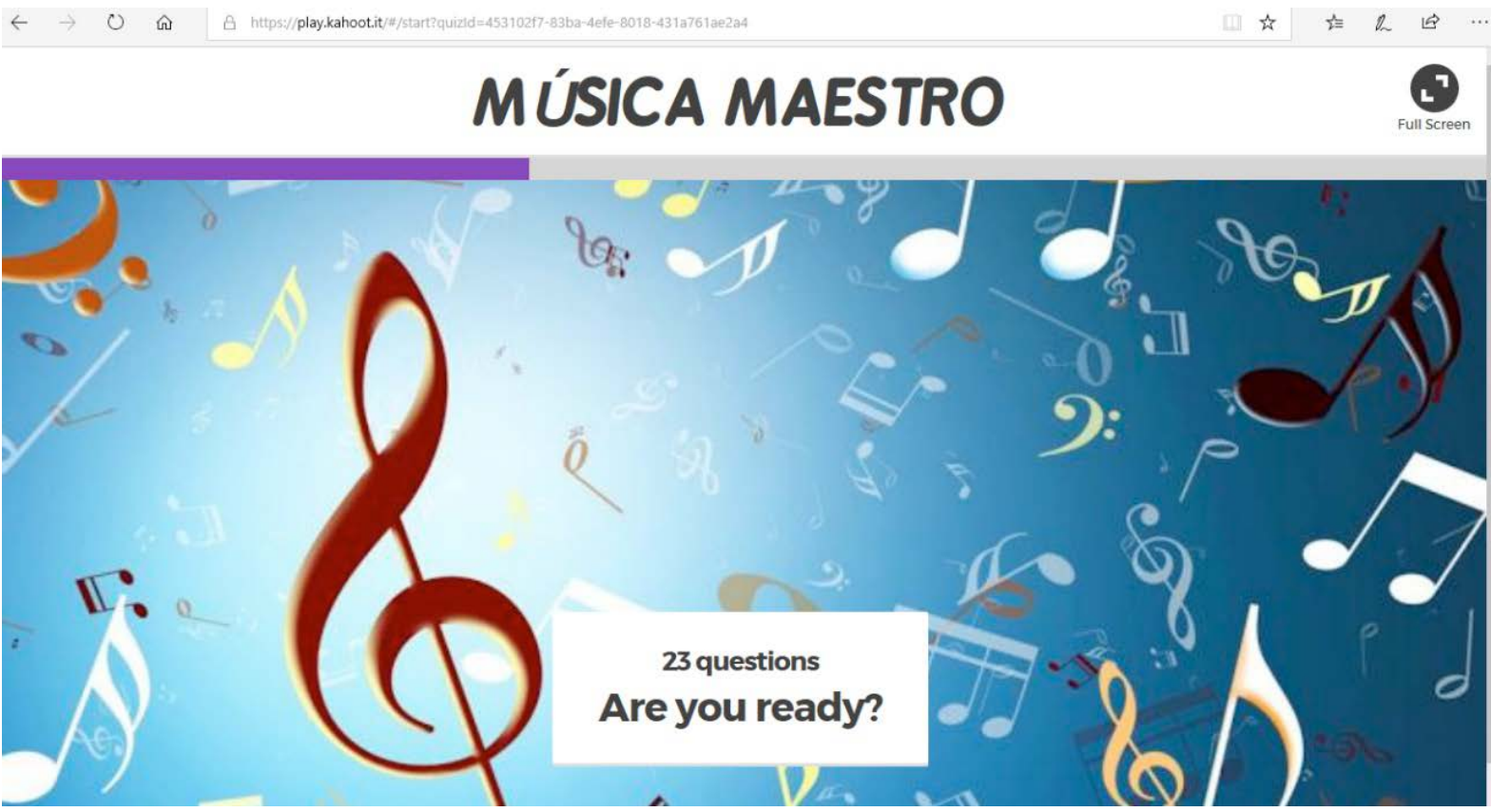

Imagen 6. Kahoot: música maestro.

D https://play.kahoot.it/\#/2quizld=453102f7-83ba-4efe-8018-431a761ae2a4

\section{Kahoot!}

\section{MÚSICA MAESTRO}

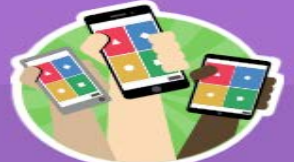

Player vs Player 1:1 Devices

Classic

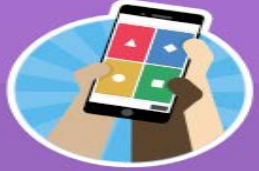

Team vs Team Shared Devices

Team mode

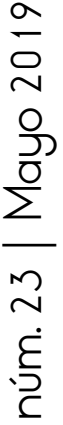

Imagen 7. Kahoot: música maestro. 
A continuación, mostramos algunos ejemplos de preguntas que aparecen en este Kahoot (Imagen 8, 9, 10, 11):

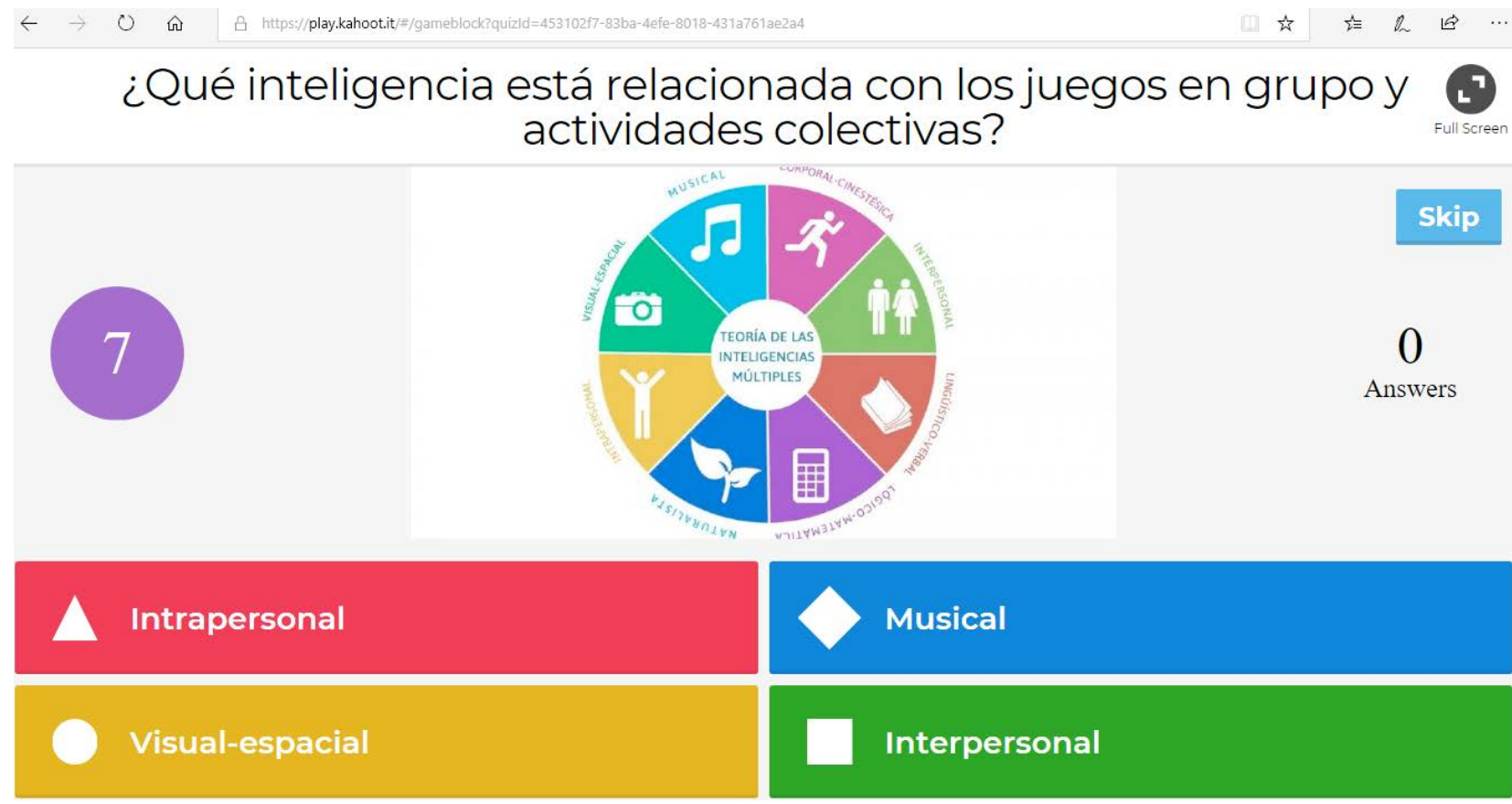

Imagen 8. Kahoot: música maestro.

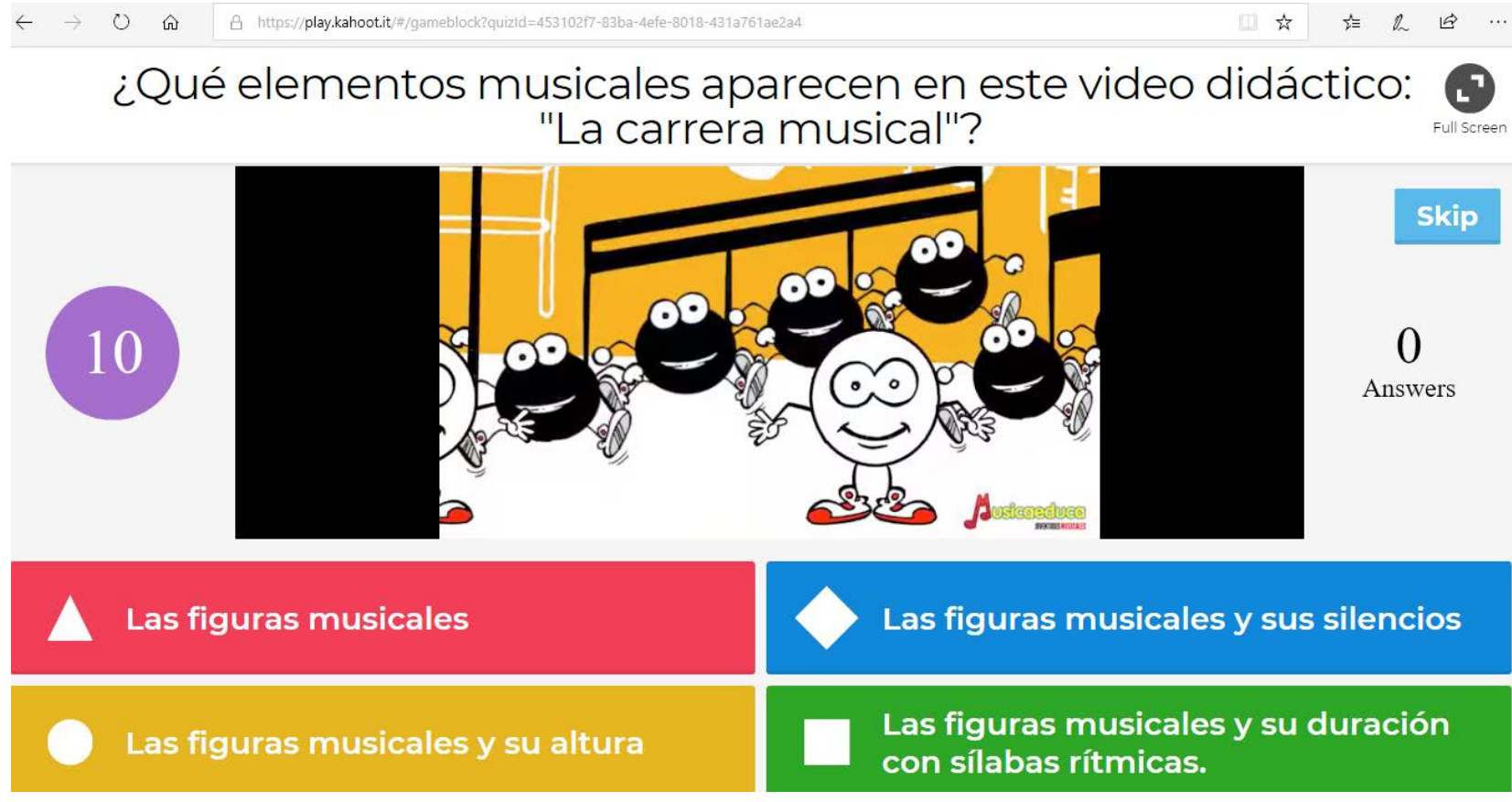

Imagen 9. Kahoot: música maestro. 


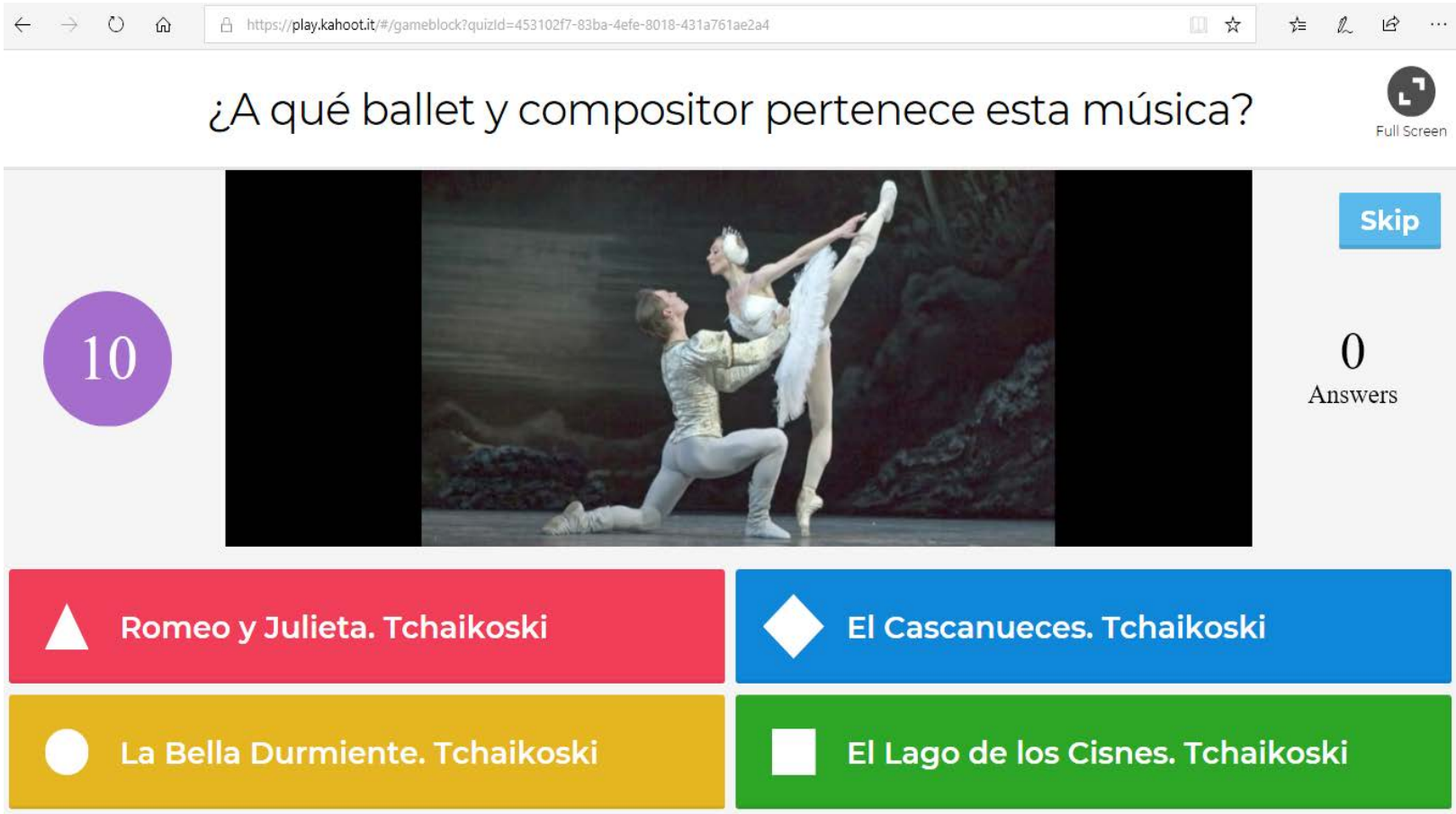

Imagen 10. Kahoot: música maestro.

¿A qué ópera pertenece esta famosa aria? ¿Qué tres tenores la ? interpretan?
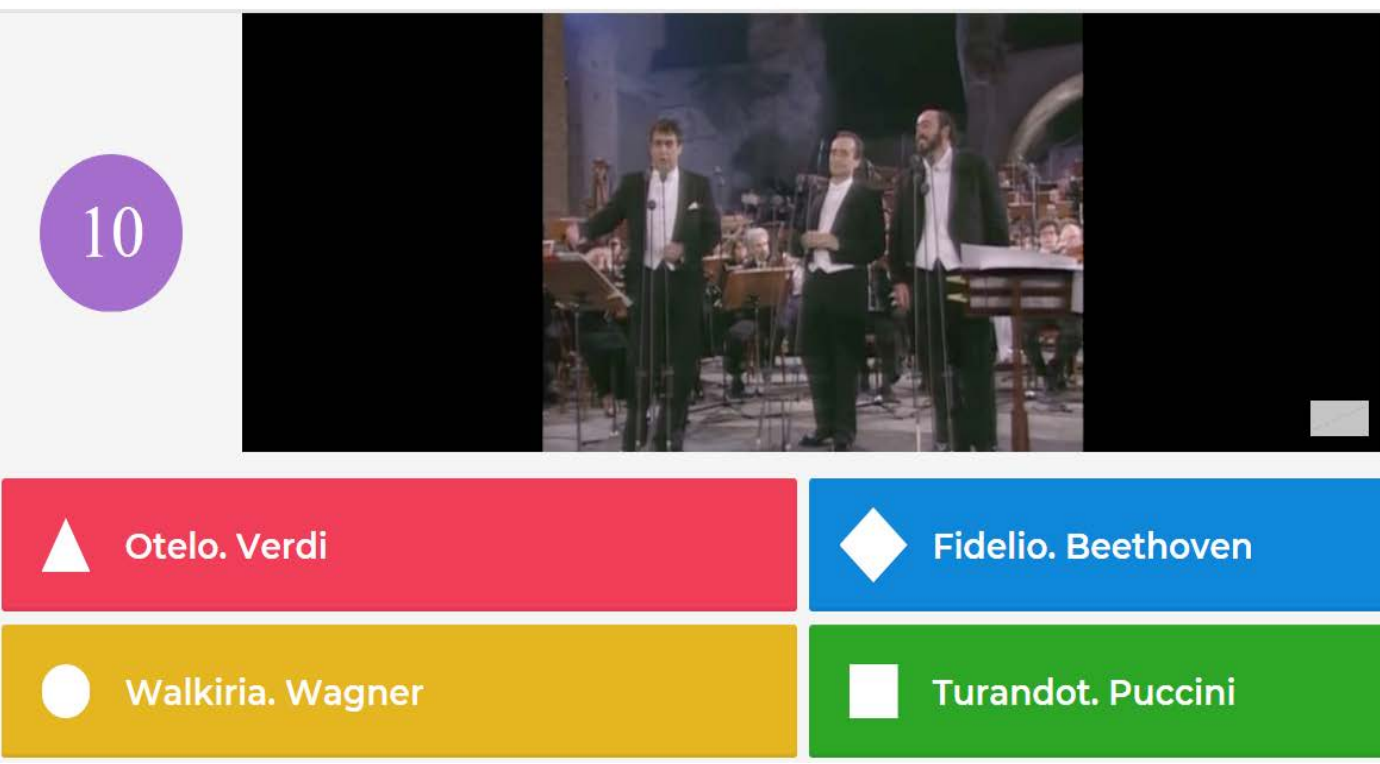

Fidelio. Beethoven

Imagen 11. Kahoot: música maestro. 


\section{Metodología cooperativa y la gamificación como instrumento de aprendizaje}

Con nuestro proyecto fundamentado en la enseñanza de la Música a través de la metodología cooperativa y la gamificación, pretendemos aportar nuevas formas de enseñar y aprender, una nueva metodología, cuya función sea la de contribuir a un aprendizaje mucho más eficiente, consolidado y activo por parte de los alumnos, para modificar ciertas prácticas "tradicionales" en la Educación Superior, propiciando el interés y la motivación del alumnado por la asignatura de Música, pues en muchos contextos universitarios, buena parte de las clases de Lenguaje Musical o Historia de la Música, siguen teniendo un enfoque mayormente memorístico, caracterizado por el relato descriptivo y enumerativo de conceptos y temas, con una baja o ausente participación del alumnado en el desarrollo de las clases. Igualmente, a través de esta propuesta lúdica-educativa, intentamos fomentar el aprendizaje significativo, el trabajo en equipo y el desarrollo personal de cada educando. Destacamos en todo el proceso la creación del conocimiento de forma proactiva y participativa mediante la creatividad y la innovación, propiciando algunas de las habilidades más demandadas en una sociedad hiperconectada que avanza, y evoluciona de manera exponencial.

En este sentido, coincidimos con los planteamientos de Robert Swart, creador del método "Thinking Based Learning", que apuesta por una reforma educativa en la que el proceso de memorización debe quedar relegado en un segundo plano. Contempla una serie de medidas como la puesta a disposición de los alumnos por parte de los profesores, de herramientas para aprender a pensar, no solo memorizar, pues está demostrado que, con el pensamiento activo, los estudiantes no solo se interesan y aprenden más, sino que desarrollan importantes capacidades relacionadas con el pensamiento que pueden usar el resto de sus vidas. Entendemos que la reflexión y el análisis de todos estos elementos es una necesidad para que el contexto de la Educación Superior pueda llegar a asegurar un proyecto complementario que dé respuesta a las demandas y necesidades sociales en el siglo XXI. 
En este ámbito, son muchos los autores y especialistas que destacan la gran relevancia del aprendizaje cooperativo y como el alumno aprende como resultado de la interacción y el trabajo con otros sobre todo en el contexto de la Educación Superior (Prieto, 2007; León del Barco y Latas, 2007; Pujolás, 2008; Guerra, 2011; Camilli, López y Barceló, 2012, Torrego y Negro, 2012; Swart, 2013; García y González, 2013; Zariquiey, 2016), entre otros. Todos ellos coinciden en que el aprendizaje cooperativo es aquel que propone que los estudiantes deben trabajar juntos para el logro de un objetivo común, mediante el uso instructivo de grupos pequeños para que los estudiantes trabajen juntos, y es que la interacción entre iguales actúa como motor de aprendizaje, cobrando especial importancia en la construcción del conocimiento. Por tanto, todas sus propuestas revelan la influencia que tiene la aplicación de esta metodología en la mejora del desarrollo académico, personal y social del alumno.

Igualmente, destacamos la gamificación, como una metodología especialmente significativa e innovadora en el ámbito educativo, subrayando su contribución para motivar al alumnado y facilitar la adquisición de aprendizajes (Wouters y Van Oostendorp, 2013; Ke, 2014; Burke, 2014; Filscker y Hickey, 2014; Riemer y Schader, 2015; Teixes, 2015; Mouws y Bleumers, 2015; Hamari et al., 2016) pues se ha demostrado que la metododología asentada en la práctica de la teoría del juego o la gamificación, se ha consolidado como una práctica innovadora en el contexto educativo para potenciar la creatividad y el talento en las aulas, al desarrollar cualquier aprendizaje actuando sobre la motivación para la consecución de objetivos concretos. Por tanto, todo ello, se postula como una opción con gran proyección educativa.

A este respecto, el objetivo de esta propuesta educativa pretende comprobar la eficacia de la aplicación de la metodología de aprendizaje cooperativo y la gamificación en el aula, así como medir el grado de satisfacción creado entre el alumnado. En suma, este proyecto de innovación encuentra el marco idóneo para establecer la conexión entre teoría y práctica, entre la aplicación de conocimientos y el desarrollo de habilidades, entre la escuela y la vida. El trabajo que presentamos pretende aportar algunas ideas que nos permitan proyectar pro- 
cesos educativos transformadores dentro del ámbito universitario, para lograrlo seguiremos una metodología abierta, flexible, participativa y comunicativa, mediante actividades en gran y pequeño grupo donde se fomente el diálogo, la cooperación y el trabajo en equipo y donde el alumno pueda pensar y comportarse de forma autónoma, racional y creativa, utilizando propuestas pedagógicas y enfoques metodológicos interesantes para aplicar posteriormente en sus aulas.

\section{Resultados y discusión}

- Análisis de los resultados

La evaluación se obtiene mediante dos instrumentos de análisis fundamentalmente: En primer lugar de la observación directa del profesorado, a partir del conocimiento, participación e intervenciones significativas por parte de los alumnos en la realización de los recursos TIC y la gamificación trabajados en el aula, de otro lado, de las respuestas del alumnado en la encuesta online, mediante la aplicación Google Drive, cumplimentado por los alumnos, para valorar la eficacia de estos materiales y apreciar los posibles cambios registrados a lo largo de todo el proceso.

En cuanto al contexto educativo y curricular, dicha encuesta, se ha realizado a 105 alumnos del Grado de Educación Primaria que se imparten dentro de los estudios de la Universidad Camilo José Cela (UCJC) en las asignaturas de Lenguaje Musical e Historia de la Música en la Mención en Música, y está constituida por 15 ítems que podemos encontrar en la siguiente URL: Application Google Drive: https://goo.gl/ forms/HWcLtISK5jcGelZE3 


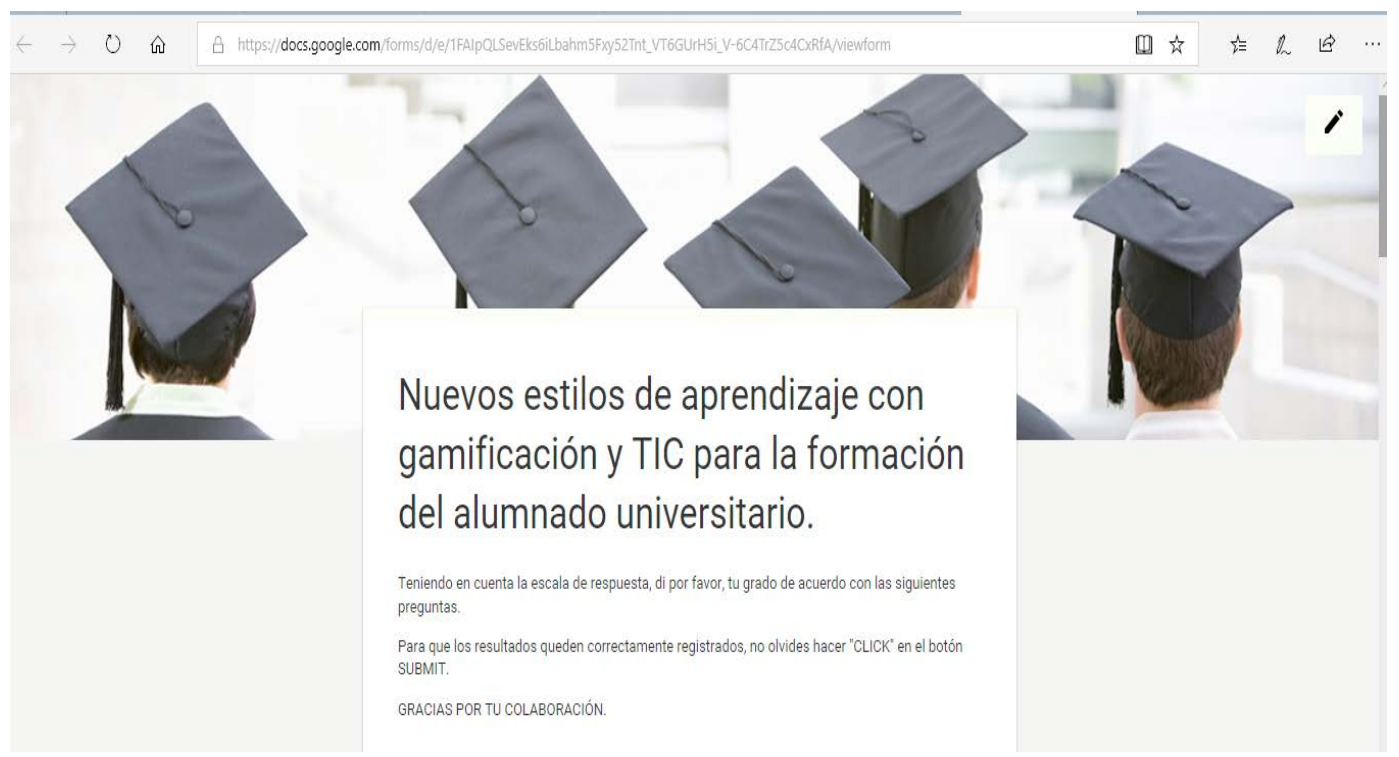

Imagen 12. Encuesta de satisfacción: Nuevos estilos de aprendizaje con gamificación y TIC para la formación del alumnado universitario.

Las preguntas planteadas son las que pueden verse en la tabla 1. con las siguientes indicaciones: contesta las siguientes preguntas y elige la respuesta más adecuada o que se acerque más a tu opinión (marcando con una $X$ ) y valora de 1 a 5 , siendo 1 el valor mínimo y 5 el valor máximo.

Tabla 1. Encuesta de satisfacción del alumnado

\begin{tabular}{|c|l|}
\hline ÍTEMS & \multicolumn{1}{|c|}{ PREGUNTAS } \\
\hline 1 & $\begin{array}{l}\text { ¿Piensas que para el desarrollo de las prácticas en la Universidad la elabora- } \\
\text { ción de materiales digitales puede ser un instrumento válido para el apren- } \\
\text { dizaje de la asignatura de música en el Grado de Primaria? }\end{array}$ \\
\hline 2 & $\begin{array}{l}\text { ¿Crees que estos recursos didácticos y multimedia y de gamificación contri- } \\
\text { buyen a mejorar tus conocimientos en la Mención de Música? }\end{array}$ \\
\hline 3 & $\begin{array}{l}\text { ¿Consideras necesario que los futuros profesores de Primaria e Infantil ad- } \\
\text { quieran conocimientos o competencias en las nuevas tecnologías? }\end{array}$ \\
\hline 4 & $\begin{array}{l}\text { ¿Crees adecuada la utilización de las nuevas tecnologías y la gamificación } \\
\text { para el aprendizaje de cualquier asignatura? }\end{array}$ \\
\hline 5 & $\begin{array}{l}\text { ¿Consideras que el uso de las nuevas tecnologías y la gamificación mejora y } \\
\text { complementa las tradicionales formas de enseñar y aprender? }\end{array}$ \\
\hline 6 & $\begin{array}{l}\text { ¿Crees que este método de aprendizaje y enseñanza ha mejorado tu com- } \\
\text { prensión de la asignatura? }\end{array}$ \\
\hline
\end{tabular}




\begin{tabular}{|c|l|}
\hline 7 & $\begin{array}{l}\text { ¿Crees que este método de aprendizaje favorece el esfuerzo y cooperación } \\
\text { de todos los alumnos? }\end{array}$ \\
\hline 8 & $\begin{array}{l}\text { ¿Consideras que estos estilos de aprendizaje pueden mejorar la práctica do- } \\
\text { cente y contribuir a una educacion de calidad? }\end{array}$ \\
\hline 9 & ¿Crees adecuado aprender de forma meramente memorística? \\
\hline 10 & $\begin{array}{l}\text { ¿Valorarías de forma más positiva el aprendizaje de la asignatura mediante } \\
\text { libros de texto exclusivamente? }\end{array}$ \\
\hline 11 & $\begin{array}{l}\text { ¿Piensas que la enseñanza en la actualidad necesita de la incorporación de } \\
\text { las nuevas tecnologías y la gamificación? }\end{array}$ \\
\hline 12 & $\begin{array}{l}\text { ¿Crees que la utilización de la gamificación y el aprendizaje a través del } \\
\text { juego ha mejorado el aprendizaje y la motivación por la asignatura en la } \\
\text { Mención en Música? }\end{array}$ \\
\hline 13 & $\begin{array}{l}\text { ¿Piensas que estas formas de aprendizaje favorecen el diálogo y el trabajo } \\
\text { cooperativo en el aula? }\end{array}$ \\
\hline 14 & $\begin{array}{l}\text { ¿Consideras tu trabajo en el aula positivo y significativo mediante la utiliza- } \\
\text { ción de estos métodos? }\end{array}$ \\
\hline 15 & $\begin{array}{l}\text { ¿Crees que estas nuevas técnicas metodológicas y estilos de aprendizaje } \\
\text { enriquecen la adquisición de conocimientos y la actualización en el apren- } \\
\text { dizaje de la música? }\end{array}$ \\
\hline
\end{tabular}

Una vez puntualizados los ítems cualitativos a analizar en la anterior URL, pasamos a analizar cuantitativamente los ítems más relevantes y significativos con respecto al trabajo y aprendizaje de la asignatura mediante el trabajo cooperativo y los recursos de gamificación elaborados. Se refieren a los ítems 1, 2, 3, 7, 12 y 13, que valoran de forma muy positiva o positiva respectivamente:

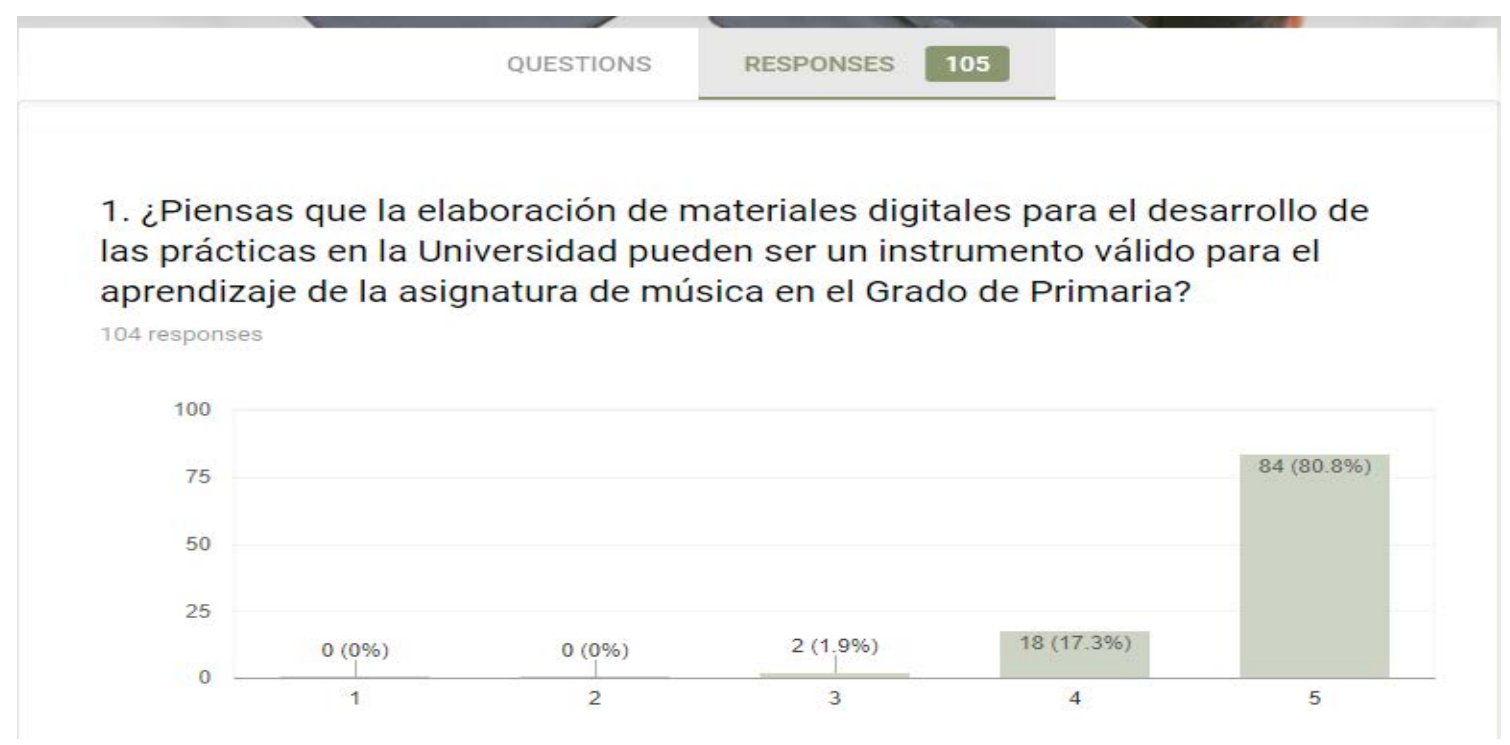

Imagen 13. Gráfico 1 
Los alumnos apoyan ampliamente la utilidad de estos materiales en el aprendizaje universitario.

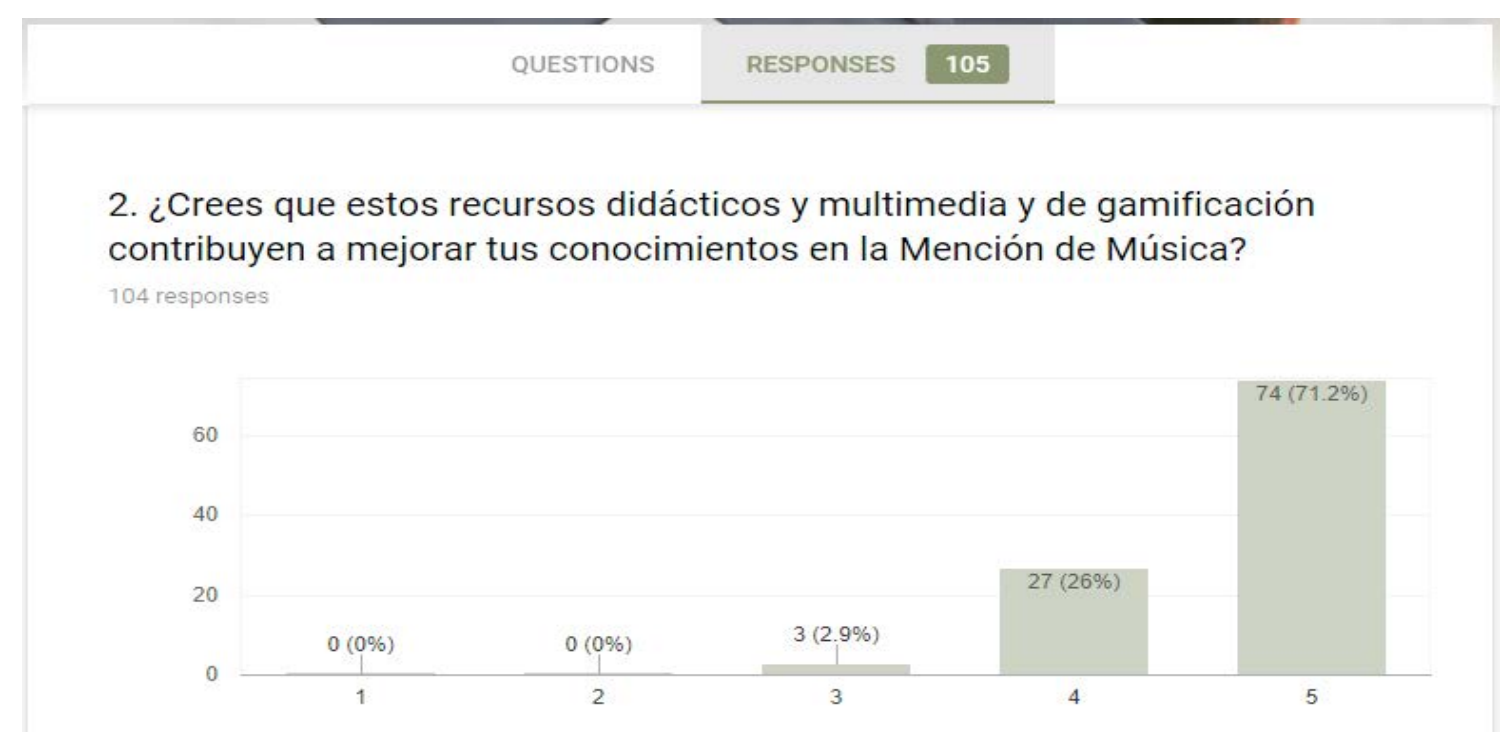

Imagen 14. Gráfico 2

Los alumnos valoran la contribución de estos recursos a la mejora de sus conocimientos en la asignatura.

3. ¿Consideras necesario que los futuros profesores de Primaria e Infantil adquieran conocimientos o competencias en las nuevas tecnologías?

104 responses

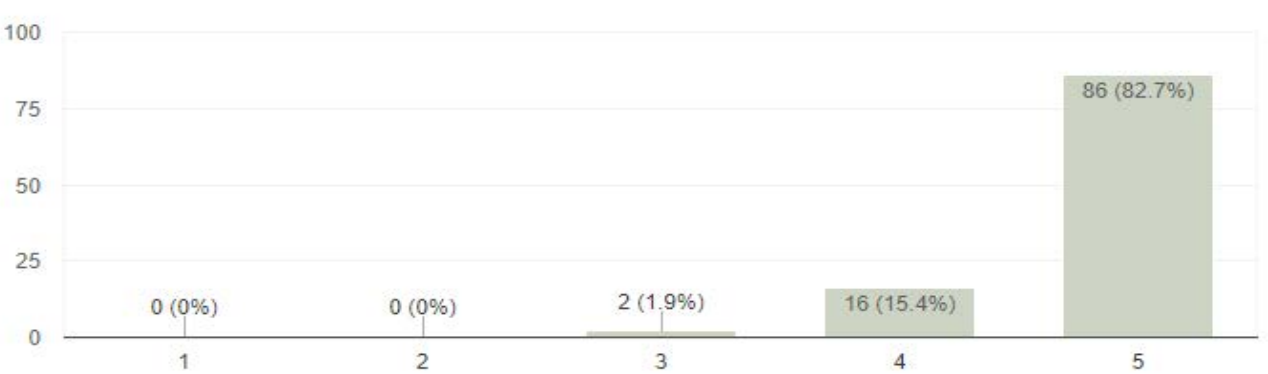

Imagen 15. Gráfico 3 
La gran mayoría reconoce la necesidad de la adquisición de conocimientos en nuevas tecnologías.

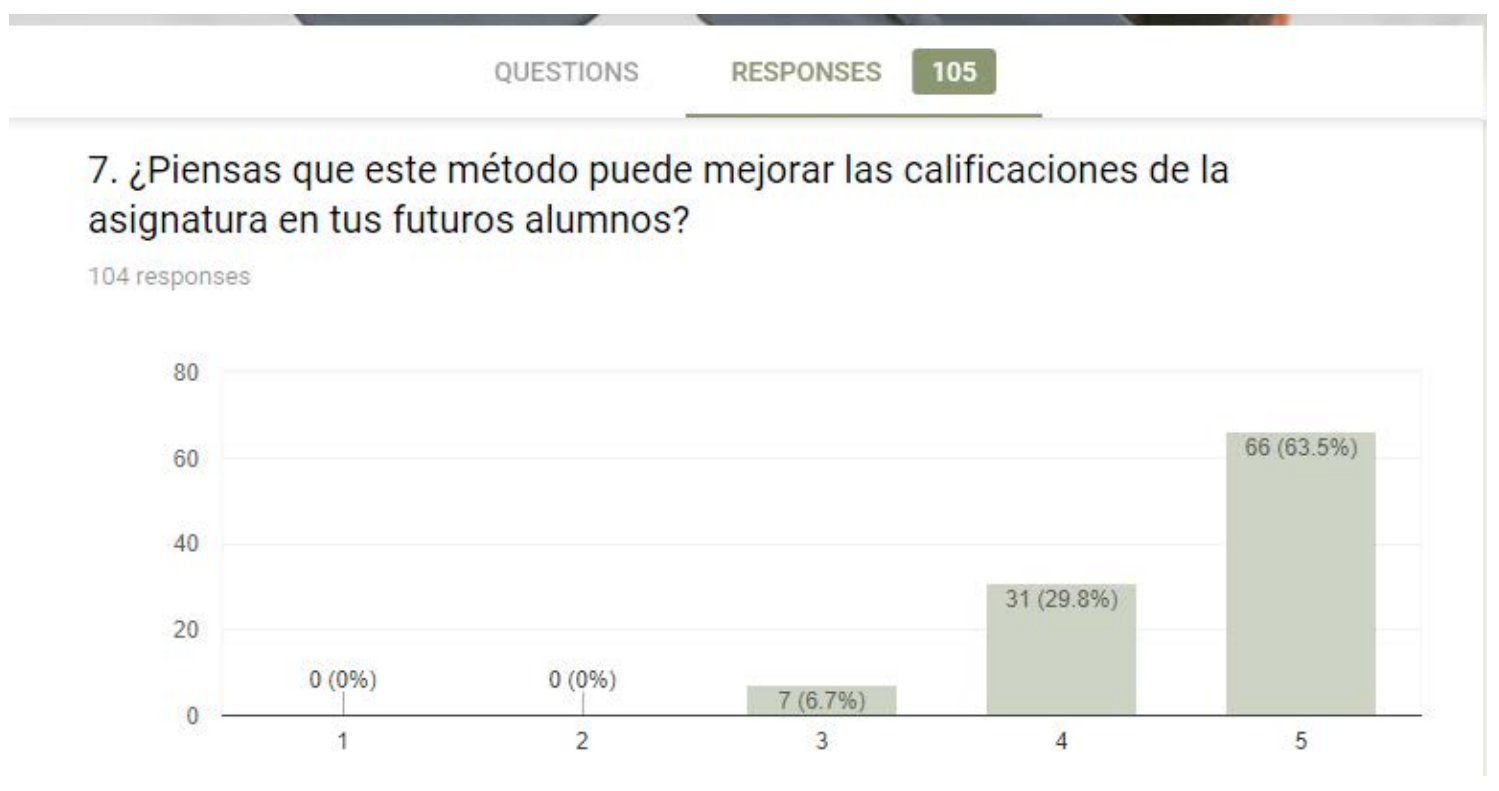

Imagen 16. Gráfico 4.

Estas herramientas de aprendizaje las consideran adecuadas para mejorar las calificaciones y conocimientos

12. ¿ Crees que la utilización de la gamificación y el aprendizaje a través del juego ha mejorado el aprendizaje y la motivación por la asignatura de Música?

104 responses

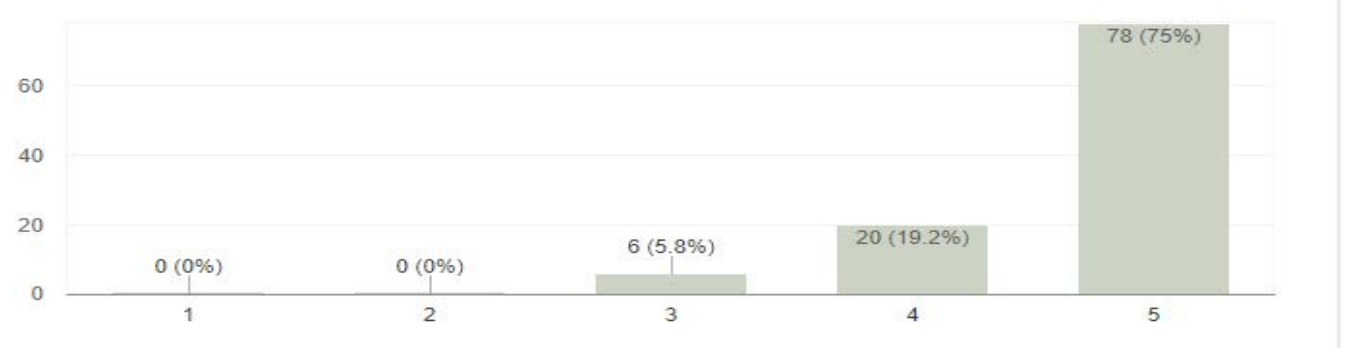

Imagen 17. Gráfico 5 
Los alumnos valoran la necesidad de emplear la gamificación para la mejora del aprendizaje, confirmando la hipótesis y utilidad de nuestro trabajo.

\section{QUESTIONS RESPONSES 105}

13. ¿Piensas que estas formas de aprendizaje favorecen el diálogo y el trabajo cooperativo en el aula?

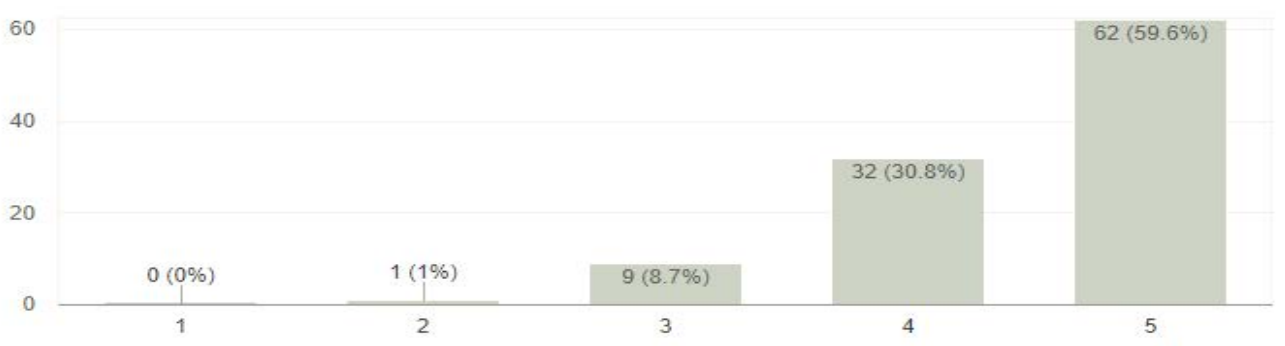

Imagen 18. Gráfico 6

Confirmando igualmente, la hipótesis y el beneficio del aprendizaje a través del trabajo cooperativo.

Tabla 2. Análisis de los valores más representativos de la encuesta.

\begin{tabular}{|c|c|c|c|c|c|}
\hline ITEMS & VALORES \% & DEL 1 I & ACUERDO & AL $5 \mathrm{M}$ & UERDO \\
\hline VALORES \% & 1 & 2 & 3 & 4 & 5 \\
\hline 1 & 0 & 0 & 1.9 & 17.3 & 80.8 \\
\hline 2 & 0 & 0 & 2.9 & 26 & 71.2 \\
\hline 3 & 0 & 0 & 1.9 & 15.4 & 82.7 \\
\hline 7 & 0 & 0 & 6.7 & 29.8 & 63.5 \\
\hline 12 & 0 & 0 & 5.8 & 19.2 & 75 \\
\hline 13 & 0 & 1 & 8.7 & 30.8 & 59.6 \\
\hline
\end{tabular}

Los resultados de esta encuesta distribuida a los alumnos muestra resultados satisfactorios, expone el beneficio de la experiencia y verifica la hipótesis de nuestro trabajo. 
Comprobamos un consenso casi generalizado de acuerdo o muy de acuerdo, respecto a la utilización de la gamificación y las nuevas tecnologías en las respuestas a los 15 ítems propuestos para el aprendizaje de los diversos contenidos musicales, reflejados como representativos en la tabla anterior:

1- Los alumnos consideran que la elaboración de materiales digitales y de gamifiacción para el desarrollo de las clases en la Mención en Música puede ser un instrumento válido para el aprendizaje de contenidos musicales.

2- Inciden en el mejoramiento del aprendizaje de la asignatura de Música.

3- Consideran necesario que los futuros docentes de Primaria adquieran competencias en nuevas tecnologías.

7- El aprendizaje con estos métodos pueden mejorar las calificaciones de sus futuros alumnos.

12- La utilización de la gamificación y la enseñanza a través del juego mejora el aprendizaje y la motivación por la asignatura de Música.

13- Consideran que estas formas de aprendizaje favorecen el diálogo y el trabajo cooperativo en el aula. Y que podríamos llamar valorativas, porque no se basan tanto en experiencias personales de los individuos sino en la consideración que tienen del fenómeno.

Paralelamente, hemos incluido los ítems 9 y 10 que interpelan acerca de la valoración de forma más positiva del aprendizaje de la asignatura de música, mediante el aprendizaje meramente memorístico y mediante la utilización del libro de texto exclusivamente, sin embargo, no se encuentran discrepancias significativas con ítems negativos, con respecto a las respuestas anteriores a pesar de ser en su mayoría alumnos acostumbrados a la memorización. 
9. ¿Crees adecuado aprender de forma meramente memorística?

104 responses

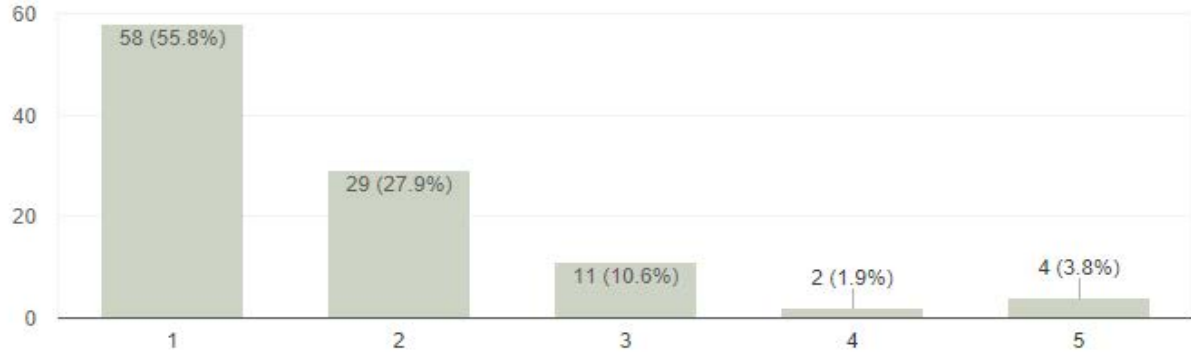

Imagen 19. Gráfico 7

Los alumnos valoran negativamente el aprendizaje memorístico.

10. ¿Valorarías de forma más positiva el aprendizaje de la asignatura mediante libros de texto exclusivamente?

104 responses

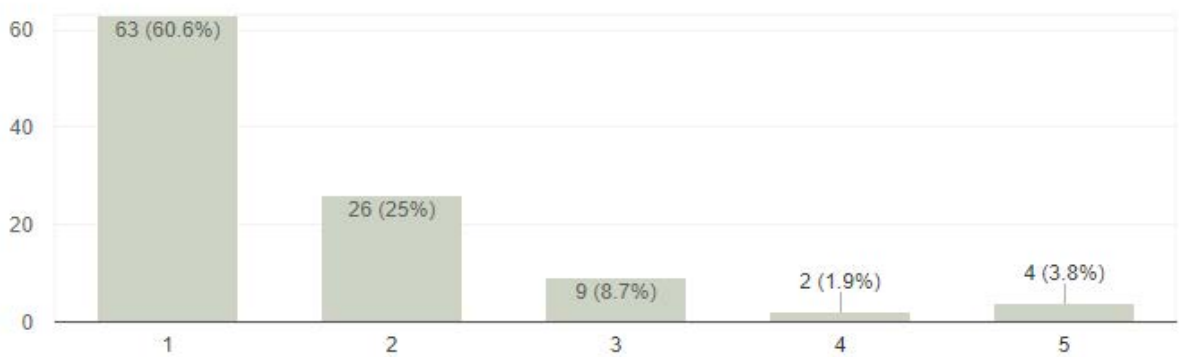

Imagen 20. Gráfico 8

La gran mayoría de alumnos consideran negativo el aprendizaje de la asignatura meramente con libros de texto, lo que confirma la utilidad de la experiencia.

Por tanto, a partir de los datos obtenidos en la evaluación del aprendizaje de los alumnos y en el análisis de los resultados, se puede verificar y, en consecuencia, corroborar que la valoración del alumnado en la consecución de estas competencias es 
significativamente más positiva tras la implantación en el aula del aprendizaje cooperativo. Por tanto, los estudiantes consideran que no solo aprenden más, sino que su aprendizaje es de más calidad con esta metodología, desarrollando una serie de competencias esenciales en la formación universitaria y muy valiosa también para el ámbito profesional.

\section{Conclusión}

La puesta en práctica de nuestra investigación y su potencial formativo permite emplear la tecnología con fines educativos o didácticos, avanzar en propuestas innovadoras que generan la construcción del conocimiento, integrando la teoría y la práctica, proporcionando a los alumnos situaciones significativas y dinámicas, mejorando la comunicación, la calidad educativa con preferencia en los aprendizajes de la música en las aulas de forma activa. Así y teniendo en cuenta las oportunidades y herramientas que la educación ofrece y los avances tecnológicos, con nuestra propuesta de innovación educativa, se demuestra la eficacia de la metodología cooperativa y la gamificación, para lo cual se emplean técnicas participativas como los Cerebriti y el Kahoot elaborados.
En síntesis, estas aportaciones pueden ser utilizadas para fomentar el aprendizaje en otras áreas de enseñanza y son lo suficientemente elocuentes como para indicarnos que hemos de pensar en cómo cambiar nuestras prácticas de metodología didáctica, deberíamos reflexionar sobre lo que aprende en realidad nuestro alumnado y lo que queremos que aprenda, para afrontar con éxito las demandas de la sociedad. Por todo ello, creemos que nuestro trabajo demuestra que la metodología cooperativa, activa, dinámica y lúdica se presenta como una alternativa, de gran potencial formativo para los alumnos, los futuros profesionales de la educación, en la medida que desarrolla la construcción colectiva del conocimiento de una forma crítica y reflexiva, que tiene relación con su futuro trabajo profesional en el contexto de la sociedad actual. Por tanto, esta experiencia educativa podría servir como punto de partida para abrir nuevas líneas de investigación académicas en torno al empleo de la metodología cooperativa y la gamificación en la docencia, concretamente en ámbito de la Educación Superior, no solo en la asignatura de Música sino también en otras materias del currículum. 


\section{Referencias}

Burke, B. (2014). Gamify: How Gamification Motivates People to do Extraordinary Things. Boston: Bibliomotion, INC.

Cabero J. (2014). Formación del profesor universitario en TIC. Aplicación del método Delphi para la selección de los contenidos formativos. Educación XXI, 17 (1), 109-132.

Camilli C, López E. y Barceló, L. (2012). Eficacia del aprendizaje cooperativo en comparación con situaciones competitivas o individuales. Su aplicación en la tecnología: Una revista sistemática. Enseñanza \& Teaching, 30, 81-103.

Contreras, R. S. y Eguia., J. L. (2016). Gamificación en aulas universitarias. Bellatera: Institut de la Comunicació. Barcelona.

Cordero, M. (2018). El éxito de la pizarra digital en las aulas. Publicaciones didácticas, 92, 183-185.

Espeso, P. (2017). 15 herramientas de gamificación para el aula que engancharán a tus alumnos. Educación 3.0. La revista para el aula del siglo XXI. 26 (45).

Filsecker, M. y Hickey, D. T. (2014). A multilevel analysis of the effects of exter- nal rewards on elementary students' motivation, engagement and learning in an educational game. Computers \& Education, 75, 136-148.

García, M. y González, N. (2013). El aprendizaje cooperativo en la Universidad. Valoración de los estudiantes respecto a su potencialidad para desarrollar competencias. Revista Iberoamericana para la Investigación y el Desarrollo Educativo. 4 (7), 106-128. 
Guri- Rosenblit, S. (2010). Digital Technologies in Higher Education: Sweeping Expectations and Actual Effects. New York: Nova Science.

Guerra M. (2011) Aprendizaje cooperativo. Una metodología con futuro. Principios y aplicaciones. Estudios Sobre Educación, 21, 240-241.

Hamari, J., Shernoff, D. J., Rowe, E., Coller, B., Asbell-Clarke, J. y Edwards, T. (2016). Challenging games help students learn: An empirical study on engage- ment, flow and immersion in game-based learning. Computers in Human Be- havior, 54, 170179.

León del Barco, B. y Latas, C. (2007). La Formación en técnicas de Aprendizaje Cooperativo del Profesor Universitario en el Contexto de la Convergencia Europea, 2, 269-277.

Mouws, K. y Bleumers, L. (2015). Co-creating Games with Children: A case Study. International Journal of Gaming and Computer-Mediated Simulations, 7(3), 22- 43.

Kaap, K.M. (2012). The Gamification of Learning and Instruction: Game- based Methods and Strategies for Training and Education. San Francisco: Jhon Wiley \&Sons, Inc.

Ke, F. (2014). An implementation of design-based learning through creating educational computer games: A case study on mathematics learning during design and computing. Computers \& Education, 73, 26-39.

Papastergiou, M. (2009). Digital Game- Based Learning in high school Computer Science education: Impact on educational effectiveness and student's motivation. Computer \& Education, 52 (1), 1-12. 
Pujolás P. (2008). 9 ideas clave: aprendizaje cooperativo. Barcelona, España, Graó,

Prado, E. (2014). Juegos como element docente en un entorno TIC. Revista Aequitas: Estudios sobre Historia, Derecho e Instituciones, 4, 407-416.

Prieto, L. (2007). La enseñanza universitaria centrada en el aprendizaje cooperativo. Barcelona: Octaedro.

Rangel, A. (2015). Competencias docentes digitales: propuesta de un perfil. PixelBit. Revista de Medios y educacion, 46, 235-248.

Riemer, V. y Schrader, C. (2015). Learning with quizzes, simulations, and adventures: Student's attitudes, perceptions and intentions to learn with different types of serious games. Computer \& Education, 88, 160-168.

Roca, F. (2004). Creatividad y comunicación musical desde las nuevas tecnologias. Comunicar. Revista Científica de Comunicación y Educación, 23, 31-36.

Romero, J. B. (2004). Las nuevas tecnologías y la expresión musical, otros lenguajes en la educación. Comunicar. Revista Científica de Counicación y Educación, 23, 25-30.

Sanchez, J., Alvarez, G. J., Davila, M. A. y Mellado, V. (2017). Teaching technology: From knowing to feeling enhancing emotional and content acquisition performance through Gardner's Multiple Intelligences Theory in technology and design lessons. Journal of Technology and Science Education, 7(1), 58-79. 
Su, C.H. y Cheng, C.H. (2015). A mobile gamification learning system for improving the learning motivation and achievements. Journal of computers Assisted Learning, 31 (3), 268-286.

Teixes, F. (2015). Gamificación, motivar jugando. Barcelona: Editorial UOC.

Torrego J.C. y Negro, A. (2012). Aprendizaje cooperativo en las aulas. Madrid: Alianza.

Wouters, P. y Van Oostendorp, H. (2013). A meta-analytic review of the role of instructional support in game-based learning. Computers \& Education, 60(1), 412-425

Zariquiey, F. Cooperar para aprender. (2016). Madrid: Biblioteca Innovación educativa. S.M. 